\title{
Analisa Prediksi Algoritma Simple Moving Average Dengan Pendekatan Multi Periode
}

\author{
Nur Widjiyati \\ Email: nurwiwid@amikom.ac.id \\ Sistem Informasi, Universitas Amikom Yogyakarta
}

\begin{abstract}
Abstrak
Prediksi merupakan kegiatan dalam menggali dan meneliti pola - pola data yang sudah ada, untuk dicari trend arah data tersebut. Algoritma Simple Moving Average adalah salah satu algoritma konvensional yang dapat melakukan prediksi data time series atau runtut waktu. Algoritma Simple Moving Average memiliki model perhitungan dengan merata-rata periode sebanyak 3-6 periode, dengan memperhatikan faktor tersebut, penulis melakukan eksperimen dengan menguji cobakan algoritma Simple Moving Average dengan menerapkan multiperiode, dari $3-6$ periode pada 2 dataset time series yang berbeda, yaitu dataset penderita penyakit paru - paru di United Kingdom dengan periode Desember 1976 hingga Desember 1979 (37 record baris) dan dataset produksi susu tiap bulan di United Kingdom dengan periode Desember 1971 hingga Desember 1974 (37 record baris). Dataset tersebut diperoleh data repositori Data Market. Hasil dari eksperimen, diketahui algoritma Simple Moving Average dengan 3 periode, memiliki error rate MAPE paling kecil.
\end{abstract}

Kata kunci : Algoritma Simple Moving Average, Prediksi Time Series, Prediksi Runtut Waktu, Prediksi Rentet Waktu

\section{Pendahuluan}

Prediksi merupakan kegiatan dalam menggali dan meneliti pola - pola data yang sudah ada untuk dicari trend arah data tersebut. Prediksi juga tidak hanya dalam ranah klasifikasi saja tapi juga dalam ranah peramalan atau forecasting. Dataset yang digunakan dalam peramalan atau forecasting biasanya adalah data historis time series yang terikat oleh label atribut waktu.

Dalam penelitian ini, peneliti menggunakan Algoritma Simple Moving Average (SMA) dikarenakan algoritma tersebut yang cukup powerful dalam menangani prediksi jangka pendek, dataset yang digunakan adalah data yang memiliki jangka waktu sedikit. Algoritma SMA akan merata - rata angka aktual sebanyak n periode yang telah ditentukan. Dalam melakukan analisa peramalan terdapat pilihan - pilihan periode dimulai dari $3-6$ periode. Peneliti mencoba untuk melakukan analisa peramalan dengan melakukan perhitungan $3-6$ periode.

Dalam melakukan penelitian eksperimen tersebut, peneliti menggunakan dataset publik yang diperoleh dari repositori datamarket, dimana terdapat 2 dataset time series : dataset penderita penyakit paru - paru di United Kingdom dengan periode Desember 1976 hingga Desember 1979 (37 record baris) ditunjukkan dengan gambar 2, dan dataset produksi susu tiap bulan di United Kingdom dengan periode Desember 1971 hingga Desember 1974 (37 record baris) ditunjukkan dengan gambar 1. Banyak baris disamakan tiap dataset agar pembanding sepadan

- Tinjauan Pustaka

Algoritma SMA adalah salah satu algoritma peramalan atau forecasting konvensional yang ada, selain algoritma tersebut terdapat beberapa model algoritma seperti AutoRegression dan Exponential Smoothing [1]. Algoritma SMA merupakan bagian dari model Moving Average dimana terdapat banyak algoritma dari model Moving Average seperti SMA, Weighted Moving Average, Exponential Moving Average dan Double Moving Average [2]. 


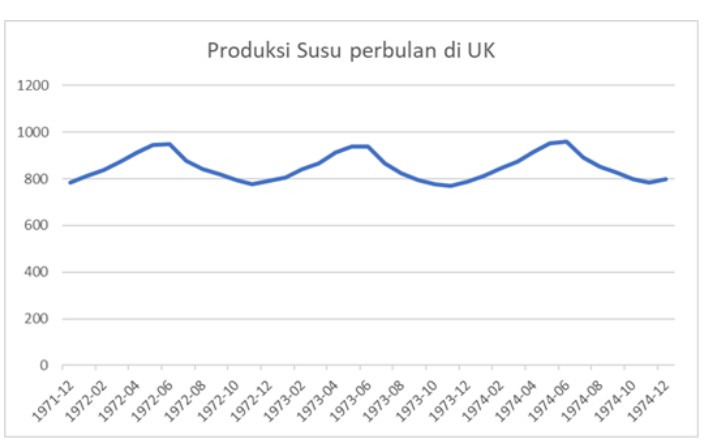

Gambar 1. Grafik plot data produksi susu perbulan di UK

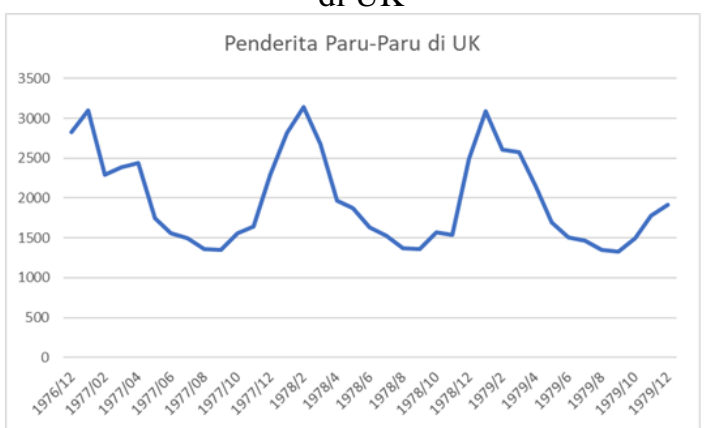

Gambar 2. Grafik plot data penderita paru - paru di UK

\section{Metode Penelitian}

Algoritma SMA merupakan bagian dari model Moving Average dimana melakukan perhitungan rata - rata sebanyak $n$ periode. Pada penelitian ini peneliti melakukan Analisa prediksi dengan memperhatikan periode prediksi $3-6$ periode.

$\hat{y}_{t+1}=\frac{y_{i-\{(n+1)}+\cdots+y_{t-13}+y_{i-2}+y_{i-1}+y_{t i}}{n}$

Dimana :

$\hat{y}=$ angka prediksi

$\mathrm{y}=$ angka aktual

$\mathrm{t}=$ waktu atau periode

$\mathrm{n}=$ banyak data aktual

MAPE $=\frac{1}{n} \sum_{t-1}^{N} \frac{\left|y_{L}-\widehat{y_{t}}\right|}{y_{\mathbb{L}}}$

(2)

Peneliti akan menggunakan formula 1 untuk melakukan perhitungan prediksi, dimana peneliti akan melakukan analisa multi periode dari periode $3-6$, hal ini dilakukan agar upaya prediksi dapat lebih tergali dan tereksplor. Hasil dari prediksi tiap periode akan di lakukan uji akurasi menggunakan metode MAPE, menggunakan formula 2.

\section{Hasil dan Pembahasan}

Dalam penelitian ini peneliti menggunakan 2 dataset public dengan jumlah record baris yang sama, hal ini ditujukan agar pembanding sepadan. Berikut detil dataset publik yang digunakan :

A. Dataset penderita penyakit paru - paru di United Kingdom dengan periode Desember 1976 hingga Desember 1979 (37 record baris)

B. Dataset produksi susu tiap bulan di United Kingdom dengan periode Desember 1971 hingga Desember 1974

Setiap dataset dilakukan eksperimen analisa prediksi trend data menggunakan sisi banyak pandangan periode, dimulai dari periode 3 bulanan, 4 bulanan hingga 6 bulanan. Proses perhitungan dan analisa dilakukan menggunakan Ms Excel menggunakan formula 1 dan 2. Tabel 1 dan 2 menunjukkan perhitungan algoritma SMA. Hasil dari prediksi tersebut dilakukan perhitungan akurasi menggunakan formula 2, seperti ditunjukkan pada tabel 3 .

Tabel 1. tabel perhitungan algoritma sma multi periode (dataset 1)

\begin{tabular}{llllll}
\hline $\mathbf{T}$ & $\mathbf{Y}$ & $\mathbf{T}(\mathbf{3})$ & $\mathbf{T}(4)$ & $\mathbf{T}(\mathbf{5})$ & $\mathbf{T}(\mathbf{6})$ \\
\hline $1976 / 12$ & 2823 & & & & \\
\hline $1977 / 01$ & 3102 & & & & \\
\hline $1977 / 02$ & 2294 & & & & \\
\hline $1977 / 03$ & 2385 & 2740 & & & \\
\hline $1977 / 04$ & 2444 & 2594 & 2651 & & \\
\hline $1977 / 05$ & 1748 & 2374 & 2556 & 2610 & \\
\hline $1977 / 06$ & 1554 & 2192 & 2218 & 2395 & 2466 \\
\hline $1977 / 07$ & 1498 & 1915 & 2033 & 2085 & 2255 \\
\hline $1977 / 08$ & 1361 & 1600 & 1811 & 1926 & 1987 \\
\hline $1977 / 09$ & 1346 & 1471 & 1540 & 1721 & 1832 \\
\hline $1977 / 10$ & 1564 & 1402 & 1440 & 1501 & 1659 \\
\hline $1977 / 11$ & 1640 & 1424 & 1442 & 1465 & 1512 \\
\hline $1977 / 12$ & 2293 & 1517 & 1478 & 1482 & 1494 \\
\hline $1978 / 1$ & 2815 & 1832 & 1711 & 1641 & 1617 \\
\hline $1978 / 2$ & 3137 & 2249 & 2078 & 1932 & 1837 \\
\hline $1978 / 3$ & 2679 & 2748 & 2471 & 2290 & 2133 \\
\hline $1978 / 4$ & 1969 & 2877 & 2731 & 2513 & 2355 \\
\hline $1978 / 5$ & 1870 & 2595 & 2650 & 2579 & 2422 \\
\hline $1978 / 6$ & 1633 & 2173 & 2414 & 2494 & 2461 \\
\hline $1978 / 7$ & 1529 & 1824 & 2038 & 2258 & 2351 \\
\hline
\end{tabular}




\begin{tabular}{llllll}
\hline $1978 / 8$ & 1366 & 1677 & 1750 & 1936 & 2136 \\
\hline $1978 / 9$ & 1357 & 1509 & 1600 & 1673 & 1841 \\
\hline $1978 / 10$ & 1570 & 1417 & 1471 & 1551 & 1621 \\
\hline $1978 / 11$ & 1535 & 1431 & 1456 & 1491 & 1554 \\
\hline $1978 / 12$ & 2491 & 1487 & 1457 & 1471 & 1498 \\
\hline $1979 / 1$ & 3084 & 1865 & 1738 & 1664 & 1641 \\
\hline $1979 / 2$ & 2605 & 2370 & 2170 & 2007 & 1901 \\
\hline $1979 / 3$ & 2573 & 2727 & 2429 & 2257 & 2107 \\
\hline $1979 / 4$ & 2143 & 2754 & 2688 & 2458 & 2310 \\
\hline $1979 / 5$ & 1693 & 2440 & 2601 & 2579 & 2405 \\
\hline $1979 / 6$ & 1504 & 2136 & 2254 & 2420 & 2432 \\
\hline $1979 / 7$ & 1461 & 1780 & 1978 & 2104 & 2267 \\
\hline $1979 / 8$ & 1354 & 1553 & 1700 & 1875 & 1997 \\
\hline $1979 / 9$ & 1333 & 1440 & 1503 & 1631 & 1788 \\
\hline $1979 / 10$ & 1492 & 1383 & 1413 & 1469 & 1581 \\
\hline $1979 / 11$ & 1781 & 1393 & 1410 & 1429 & 1473 \\
\hline $1979 / 12$ & 1915 & 1535 & 1490 & 1484 & 1488 \\
\hline & & 1729 & 1630 & 1575 & 1556 \\
\hline $196 / 2$ & Tabe perning &
\end{tabular}

\begin{tabular}{llllll}
\hline $1973-12$ & 787 & 781 & 791 & 806 & 828 \\
\hline $1974-01$ & 813 & 778 & 783 & 790 & 803 \\
\hline $1974-02$ & 846 & 791 & 787 & 789 & 794 \\
\hline $1974-03$ & 873 & 815 & 804 & 799 & 798 \\
\hline $1974-04$ & 915 & 844 & 830 & 818 & 811 \\
\hline $1974-05$ & 951 & 878 & 862 & 847 & 834 \\
\hline $1974-06$ & 961 & 913 & 896 & 880 & 864 \\
\hline $1974-07$ & 892 & 942 & 925 & 909 & 893 \\
\hline $1974-08$ & 851 & 935 & 930 & 918 & 906 \\
\hline $1974-09$ & 827 & 901 & 914 & 914 & 907 \\
\hline $1974-10$ & 797 & 857 & 883 & 896 & 900 \\
\hline $1974-11$ & 784 & 825 & 842 & 866 & 880 \\
\hline $1974-12$ & 798 & 803 & 815 & 830 & 852 \\
\hline & & 793 & 802 & 812 & 825 \\
\hline
\end{tabular}

Tabel 3. Tabel perhitungan akurasi algoritma sma menggunakan metode mape

\begin{tabular}{lllll}
\hline \multirow{2}{*}{ Dataset } & \multicolumn{4}{l}{$\begin{array}{l}\text { Rata - Rata MAPE Per } \\
\text { Periode }\end{array}$} \\
\cline { 2 - 5 } & $\mathbf{T ( 3 )}$ & $\mathbf{T ( 4 )}$ & $\mathbf{T ( 5 )}$ & $\mathbf{T}(6)$ \\
\hline $\begin{array}{l}\text { Dataset penderita } \\
\text { penyakit paru - } \\
\text { paru di UK }\end{array}$ & $22 \%$ & $26 \%$ & $30 \%$ & $32 \%$ \\
\hline $\begin{array}{l}\text { Dataset produksi } \\
\text { susu tiap bulan di }\end{array}$ & $6 \%$ & $7 \%$ & $8 \%$ & $8 \%$ \\
UK & & & & \\
\hline
\end{tabular}

Hasil eksperimen perhitungan algoritma SMA yang ditunjukkan dengan tabel 1 dan 2 , dilakukan perhitungan akurasi menggunakan metode MAPE seperti yang ditunjukkan pada tabel 3. Angka persentase pada tabel 3 merupakan rata - rata MAPE tiap periode.

Dapat diperhatikan pada tabel 3, pada 2 dataset yang berbeda tersebut ditunjukkan pada periode 3 yaitu $\mathrm{T}(3)$, menunjukkan angka persentase paling baik dibanding 3 periode yang lain. Terdapat peningkatan error margin yang naik secara simultan dari perhitungan SMA 3 periode ke 6 periode.

\section{Kesimpulan}

Berdasarkan hasil eksperimen yang telah peneliti lakukan, disimpulkan bahwa dengan mengacu pada 2 dataset yang penulis gunakan, algoritma SMA dengan rata - rata 3 periode lebih baik daripada yang lain. Jika dibandingkan dengan perata - rataan 4-6 periode, mulai dari 3 periode hingga 6 periode, terjadi peningkatan error rate, dengan error rate paling kecil ada pada 3 periode.

Saran untuk penelitian selanjutnya, penulis mengusulkan untuk melakukan 
eksperimen algoritma ARFIMA, dimana algoritma tersebut merupakan perbaikan daripada algoritma ARIMA. Pada model algoritma konvensional, ARIMA merupakan algoritma yang bagus dalam melakukan prediksi, namun algoritma ARIMA memiliki kekurangan dimana hanya dapat memprediksi rentang jangka pendek. Algoritma ARFIMA adalah perbaikan dari algoritma ARIMA.

\section{Daftar Pustaka}

[1] Irfan Abbas, 2016, PENERAPAN METODE MOVING AVERAGE (MA) BERBASIS ALGORITMA SUPPORT VECTOR MACHINE (SVM) UNTUK MEMBANDINGKAN POLA KURVA DENGAN TREND KURVA PADA TRADING FOREX ONLINE. Jurnal Ilmiah Ilkom Vol 8 No 1

[2] Surya Agustian, Heru Wibowo, 2019, Perbandingan Metode Moving Average untuk Prediksi Hasil Kelapa Sawit. SNTIKI, UIN Sultan Syarif Kasim Riau. 